\title{
Analisis Tingkat Usability Pada Aplikasi Frostid Menggunakan System Usability Scale (SUS)
}

\author{
Arista Pratama $^{1}$, Asif Faroqi ${ }^{2}$, Eka Prakarsa Mandyartha $^{3}$ \\ ${ }^{1,2}$ Program Studi Sistem Informasi, Universitas Pembangunan Nasional “Veteran”, Surabaya, Indonesia \\ ${ }^{3}$ Program Studi Informatika, Universitas Pembangunan Nasional "Veteran”, Surabaya, Indonesia \\ email: ${ }^{1}$ aristapratama.si@upnjatim.ac.id
}

\begin{abstract}
Abstrak
Banjir adalah keadaan dimana suatu daratan tergenang oleh air dalam jumlah besar yang tidak sepenuhnya mampu diserap oleh tanah. Banjir merupakan permasalahan yang sering terjadi saat musim hujan di berbagai daerah Indonesia. Jalan yang banjir membuat kerugian bagi para pengendara yang melewatinya, misalnya seperti kerusakan mesin, bahkan hingga kecelakaan. Dibutuhkan aplikasi pelaporan jalan banjir yang memberikan informasi daerah banjir sehingga pengendara dapat menghindari jalanan banjir dan menempuh jalur yang lebih baik. Aplikasi Frostid merupakan aplikasi berbasis android yang bertujuan untuk pelaporan jalan banjir secara online yang berfokus pada peta navigasi berlalu-lintas dengan melibatkan partisipasi warga secara aktif (crowdsourcing). Penelitian ini bertujuan untuk mengukur tingkat usability pada Aplikasi Frostid menggunakan analisa System Usability Scale (SUS). Hasil penelitian menunjukkan bahwa aplikasi Frostid termasuk dalam range OK dengan hasil score 59.7. Hasil perhitungan kategori satu variabel dan dua variabel keduanya menunjukkan hasil perhitungan dengan range yang berada pada kategori OK dan Good.
\end{abstract}

\section{Kata Kunci: Banjir, Frostid, Usability, System Usablity Scale.}

\section{Abstract}

The number of herbal plants found in Indonesia is 30,000 species, but only 1,200 species of all types of medicinal Flooding is a condition where a land is inundated by large amounts of water that are not fully absorbed by the soil. Flooding is a problem that often occurs during the rainy season in various regions of Indonesia. Flooded roads cause losses for motorists who pass by, such as engine damage, even accidents. A flood road reporting application is needed that provides information on flooded areas so that motorists can avoid flooded roads and take better routes. Frostid application is an android-based application that aims to report flood roads online which focuses on traffic navigation maps by involving active citizen participation (crowdsourcing). This study aims to measure the usability level of the Frostid Application using System Usability Scale (SUS) analysis. The results showed that the Frostid application was in the OK range with a score of 59.7. The results of the calculation of the category of one variable and two variables both show the results of the calculation with a range that is in the OK and Good categories.

Keywords: Flooding, Frostid, Usability, System Usablity Scale 


\section{PENDAHULUAN}

Banjir merupakan salah satu bencana alam yang merugikan masyarakat yang sering terjadi di berbagai wilayah ( $\mathrm{Li} \& \mathrm{Li}, 2011$ ). Definisi banjir adalah keadaan dimana suatu daratan tergenang oleh air dalam jumlah besar yang tidak sepenuhnya mampu diserap oleh tanah (Kodoatie \& Sugiyanto, 2002). Penyebab banjir antara lain curah hujan yang tinggi, debit air yang melebihi kapasitas drainase, dan keterbatasan daerah resapan akibat alih fungsi menjadi kawasan pemukiman (Sholihah et al., 2020). Cuaca ekstrem yang mengakibatkan banjir dapat mengganggu mobilitas manusia dan barang, yang nantinya akan berdampak pada kesejahteraan masyarakat terutama dalam perekonomian.

Banjir merupakan permasalahan yang sering terjadi saat musim hujan di berbagai daerah Indonesia (Findayani, 2015). Jalan yang banjir membuat kerugian bagi para pengendara yang melewatinya, misalnya seperti kerusakan mesin, bahkan hingga kecelakaan. Dari permasalahan diatas, perlu adanya aplikasi pelaporan jalan banjir yang memberikan informasi daerah banjir sehingga pengendara dapat menghindari jalanan banjir dan menempuh jalur yang lebih baik.

Aplikasi Frostid merupakan aplikasi berbasis android yang bertujuan untuk pelaporan jalan banjir secara online yang berfokus pada peta navigasi berlalu-lintas, dengan melibatkan partisipasi warga secara aktif (crowdsourcing). Aplikasi Frostid memiliki tampilan antarmuka yang sederhana dengan menampilkan halaman utama berupa peta navigasi berlalu-lintas yang memberikan informasi titik banjir. Pada saat instalasi, akan muncul informasi pengenalan aplikasi serta kategori banjir. Kategori banjir menunjukkan level banjir yang telah disediakan pada Aplikasi Frostid. Tampilan pada Aplikasi Frostid dapat dilihat seperti pada Gambar 1.

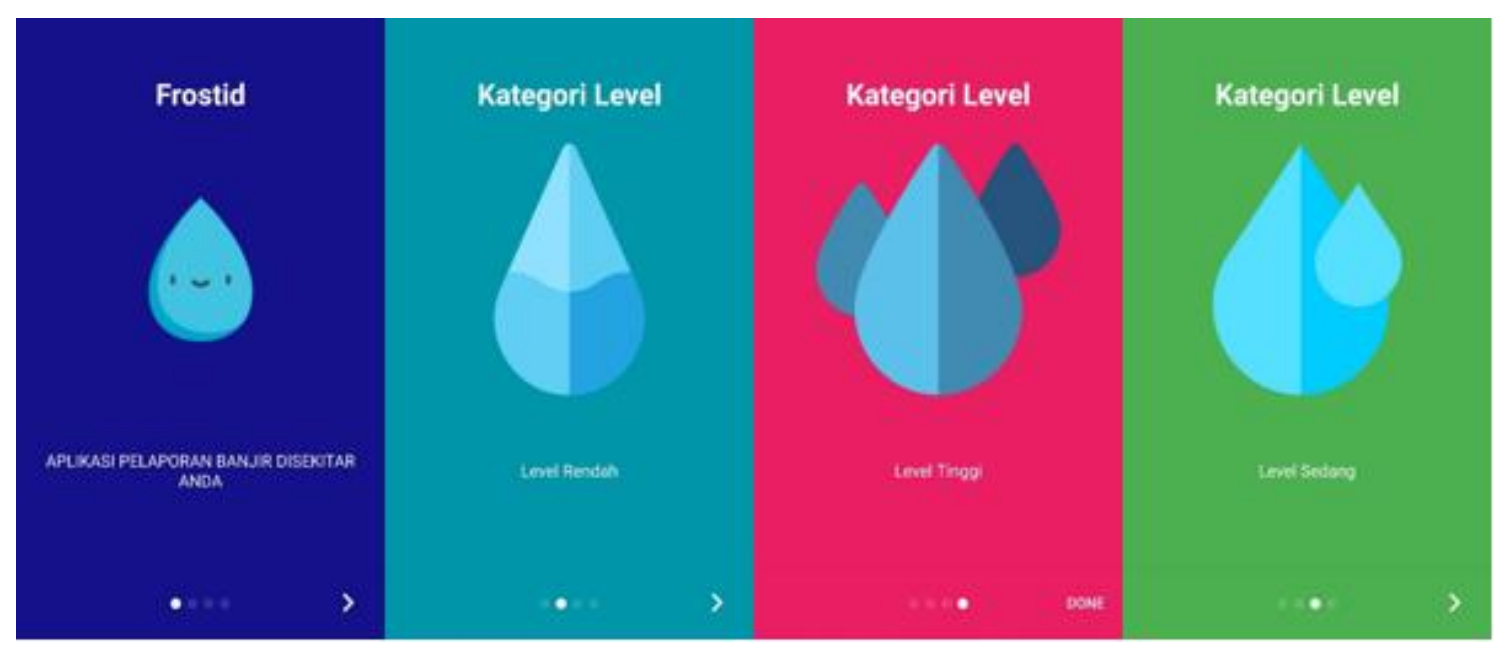

Gambar 1. Tampilan Awal Instalasi Aplikasi Frostid

Tampilan halaman utama aplikasi Frostid mengarah pada peta navigasi yang bertujuan agar pengguna dengan mudah melaporkan jalan banjir yang mereka temui. Sistem pelaporan banjir pada aplikasi Frostid mengikuti lokasi pengguna seperti pada Gambar 2.

Aplikasi Frostid berbasis crowdssourcing, sehingga tingkat usability menjadi faktor penting. Pengembangan dan evaluasi Graphic User Interface (GUI) guna mendukung fungsi aplikasi merupakan bagian penting karena berkaitan erat dengan usability. GUI membuat aplikasi lebih mudah digunakan atau dioperasikan dengan adanya gambar-gambar grafik, menu, dan ikon yang menarik (Galitz, 2007). Dengan pendekatan usability maka pengalaman pengguna seperti kemudahan, ketertarikan, dan kenyamanan pengguna saat menjalankan aplikasi dapat diketahui. Menurut ISO 9241-210 (2009) usability adalah ukuran sejauh man sebuah produk (aplikasi) dapat digunakan oleh pengguna untuk mencapai tujuan tertentu dengan efektif, efisiensi, dan kepuasan dalam penggunaan produk (aplikasi) (Nielsen, 2012). 


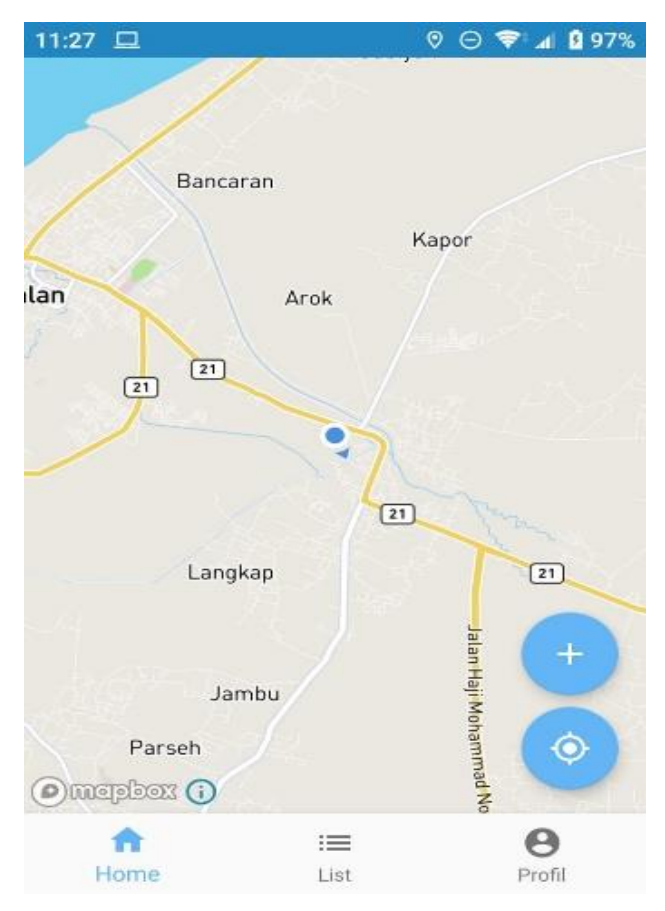

Gambar 2. Tampilan Halaman Utama (Maps)

Usability merupakan atribut kualitas yang menaksirkan bahwa bagaimana kemudahan user interface saat digunakan (Nielsen, 2012). Usability dapat dikatakan sebagai metode untuk memegang prinsip ease of use saat melakukan proses desain. Dalam buku yang berjudul The Essential Guide to User Interface Design: An Introduction to GUI Design, Quensenbery menyatakan usability dapat diukur dengan beberapa indikator yaitu 1) Effective yaitu kelengkapan dan akurasi yang didapat pengguna dalam mengerjakan tugas tertentu, 2) Efficient yaitu kecepatan dan akurasi yang didapat pengguna dalam mencapai tujuan tertentu, 3) Engaging yaitu sejauh mana warna dan gaya desain antarmuka membuat produk menyenangkan atau memuaskan pengguna saat digunakan, 4) Error tolerant yaitu seberapa baik desain dapat mencegah kesalahan dan membantu perbaikan dari hal-hal yang telah terjadi, 5) Easy to learn yaitu seberapa baik produk mendukung orientasi awal serta peningkatan pengetahuan terhadap kemampuannya (Galitz, 2007).

Metode evaluasi usability didefinisikan sebagai prosedur yang terdiri dari serangkaian aktivitas pengumpulan data penggunaan aplikasi yang terkait dengan interaksi pengguna akhir untuk mencapai tingkat kegunaan tertentu (Fernandez et al., 2011). Metode usability dibagi menjadi dua kategori yaitu metode empiris dan metode inspeksi. Metode empiris ini kemudian dibagi menjadi metode penyelidikan (misalnya wawancara, kuesioner, dan survei), dan pengujian kegunaan formal (seperti interaksi dengan situs web untuk melakukan tugas tertentu) (Battleson et al., 2001). Dalam metode empiris, penelitian didasarkan pada fenomena yang diamati dan diukur untuk memperoleh pengetahuan dan pengalaman aktual (Cahoy, 2021).

Penelitian ini bertujuan untuk mengukur tingkat usability desain user interface pada Aplikasi Frostid menggunakan analisa System Usability Scale (SUS). Penelitian ini menggunakan pengujian dan kuesioner yang berfokus pada lima komponen usability yaitu learnability, efficiency, memorability, errors dan satisfaction (Nielsen, 2012). Penelitian ini merupakan pengujian verifikasi dan validasi. Pengujian verifikasi merupakan sebuah pengecekan dimana aplikasi tersebut sudah dapat mencapai tujuannya tanpa adanya bug. Pengujian validasi merupakan proses evaluasi apakah produk yang dikembangkan sesuai dengan tujuan (Muqoddas et al., 2020). 


\section{METODE PENELITIAN}

Analisis usability desain user interface pada aplikasi Frostid menggunakan metode kuantitatif. Pengumpulan data melalui angket pengujian usability dengan menggunakan System Usability Scale (SUS). Adapun tahapan pengujian pada penelitian ini adalah:

1. Menyusun langkah-langkah yang dilakukan oleh pengguna sebelum mengisi kuesioner usability testing. Saat menggunakan aplikasi Frostid hal yang paling penting bagi pengguna adalah proses pembuatan akun beserta menjelajahi fitur-fitur yang tersedia pada aplikasi sehingga didapat langkah-langkah sebagai berikut:

a. Membuat akun Frostid. User harus memiliki akun terlebih dahulu agar dapat menggunakan aplikasi

b. Menjelajahi fitur aplikasi. Seminimal mungkin User harus sudah berada pada halaman utama (Maps) yang berisi peta navigasi berlalu-lintas yang memberikan informasi titik banjir.

2. Memilih responden. Responden dipilih secara acak dengan ketentuan responden sudah menginstal, membuat akun, dan menjelajahi fitur aplikasi.

3. Tahapan Pengujian. Responden mengisi kueisoner usability testing sesuai dengan sebelumnya mengikuti langkah-langkah yang telah dibuat seperti pada Tabel 1 .

Tabel 1. Pertanyaan SUS

\begin{tabular}{cl}
\hline No. & \multicolumn{1}{c}{ Pertanyaan } \\
\hline $\mathbf{1}$ & Saya merasa akan sering menggunakan aplikasi Frostid \\
\hline $\mathbf{2}$ & Saya menemukan bahwa aplikasinya kompleks \\
\hline $\mathbf{3}$ & Saya merasa aplikasi Frostid mudah digunakan \\
\hline $\mathbf{4}$ & Saya merasa membutuhkan technical support untuk dapat menggunakan aplikasi Frostid \\
\hline $\mathbf{5}$ & Saya merasa berbagai bentuk fitur aplikasi telah terintegrasi dengan baik satu sama lain \\
\hline $\mathbf{6}$ & Saya merasa erlalu banyak ketidakkonsistenan dalam aplikasi Frostid \\
\hline $\mathbf{7}$ & Saya dapat membayangkan bahwa akan ada banyak orang yang belajar menggunakan aplikasi \\
& Frostid secara cepat. \\
\hline $\mathbf{8}$ & Saya merasa aplikasi Frostid sangat rumit untuk digunakan \\
\hline $\mathbf{9}$ & Saya merasa sangat percaya diri saat menggunakan aplikasi Frostid \\
\hline $\mathbf{1 0}$ & Saya harus belajar banyak hal terlebih dahulu sebelum saya dapat mulai menggunakan aplikasi \\
& Frostid \\
\hline
\end{tabular}

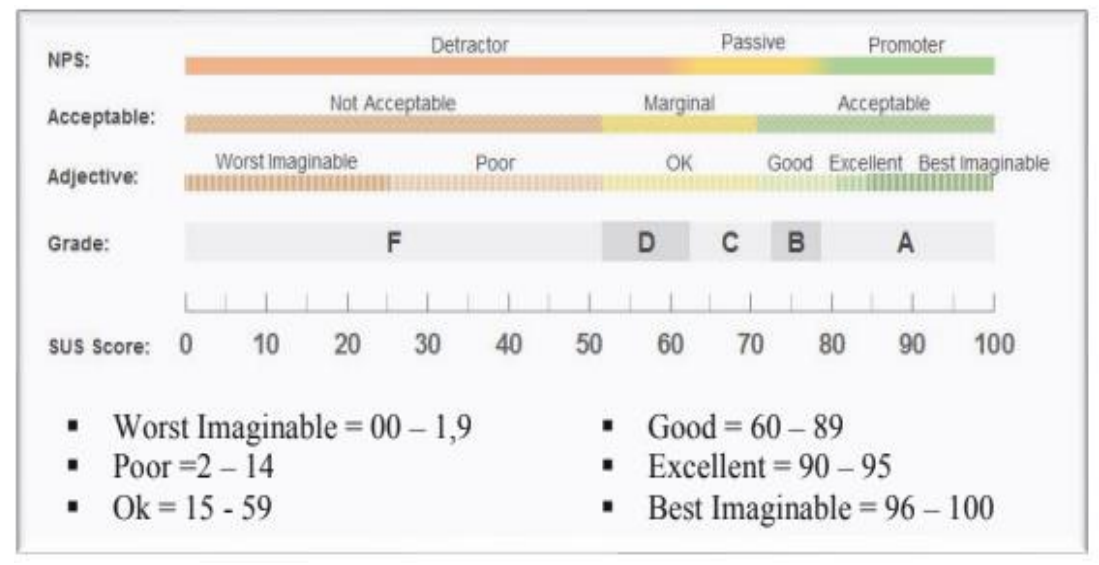

Gambar 3. Interpretasi Nilai SUS

4. Rekapitulasi hasil pengujian menggunakan SUS pada aplikasi Frostid. Analisa SUS menggunakan skala penilaian 1 hingga 5 (x) dengan bobot 0 hingga 4 dari 10 pertanyaan yang diberikan. Pertanyaan dibagi menjadi 2 yaitu pertanyaan yang bernada positif (diletakkan pada 
nomer pertanyaan 1,3,5,7 dan 9) dan pertanyaan bernada negatif (diletakkan pada nomer pertanyaan 2,4,6,8 dan 10). Untuk Pertanyaan 1,3,5,7 dan 9 nilai didapat dari skala penilaian dikurang 1 (x-1) sedangkan Pertanyaan 2,4,6,8, da 10 nilai didapat dari 5 dikurang skala penilaian $(5-\mathrm{x})$. Hasil penjumlahan dari nilai score dikalikan dengan 2.5 untuk mendapatkan nilai SUS (Brooke, 1996). Rentang hasil penilaian yang digunakan untuk penelitian ini akan diterjemahkan menggunakan adjective scale seperti yang terlihat pada Gambar 4 (Bangor et al., 2009).

\section{HASIL DAN PEMBAHASAN}

\section{A. Analisa Responden}

Berdasarkan hasil survei yang dilakukan terhadap 87 orang responden, diambil 60 orang responden yang memenuhi syarat sesuai dengan ketentuan bahwa responden harus memiliki akun beserta menjelajahi fitur seminimal mungkin halaman utama (maps) yang berisi peta navigasi berlalu-lintas yang memberikan informasi titik banjir. Dari 60 responden yang diambil diketahui bahwasanya $40 \%$ dari responden pria, dan $60 \%$ dari responden wanita. Dilihat dari usia, sebagian besar responden berasal dari umur 18-30 tahun (70\%), sisanya $<18$ tahun sebesar 7\%, 31-40 tahun 5\%, 41-50 tahun 5\%, dan >50 tahun $13 \%$. Untuk sebaran pekerjaan responden sebagai berikut:
a. Dosen/Tenaga Pendidik : Wanita (3 responden)
b. Pelajar/Mahasiswa : Pria (12 responden) dan Wanita (16 responden)
c. PNS : Pria (3 responden) dan Wanita (3 responden)
d. Wiraswasta : Pria (7 responden) dan Wanita (8 responden)
e. Wirausaha : Pria (2 responden) dan Wanita (6 responden)

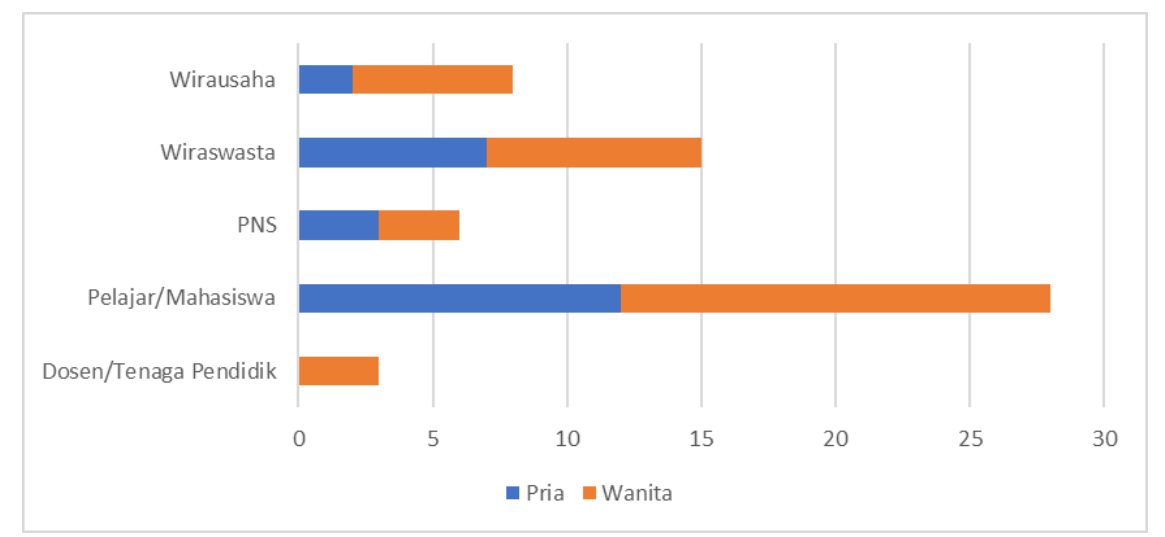

Gambar 4. Grafik Sebaran Pekerjaan dan Jenis Kelamin Pengguna

\section{B. Analisa Hasil SUS}

Hasil analisa usability dengan menggunakan SUS yang diubah dalam bentuk adjective scale. Hasil nilai SUS Aplikasi Frostid didapat dari survei yang telah dikonversi sesuai dengan bobotnya masing-masing. Hasil SUS menunjukkan bahwa secara keseluruhan Aplikasi Frostid masuk dalam range OK (cukup baik) dengan nilai 59.71 seperti pada Gambar 5.

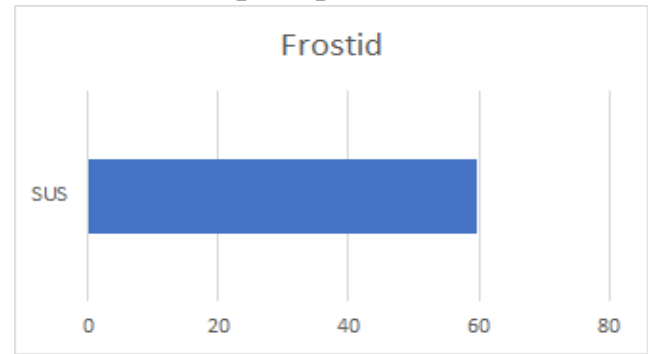

Gambar 5. Grafik Analisa Usability Aplikasi Frostid 
Untuk mendapatkan hasil penelitian yang lebih mendalam, maka penulis mencoba meneliti hasil SUS dengan membedakannya pada kategori lain yaitu dengan melihat SUS berdasarkan jenis kelamin yaitu responden pria dan wanita. Selain itu penulis juga meneliti berdasarkan kategori usia dengan rentang usia <18 tahun, 18-30 tahun, 31-40 tahun, 41-50 tahun, dan >50 tahun. Seperti yang dilihat pada gambar 5 diatas, hasil SUS final score berdasarkan kategori jenis kelamin memiliki range OK dengan SUS Final Score 57,29 pada Pria dan 59,17 pada wanita seperti pada Gambar 6.

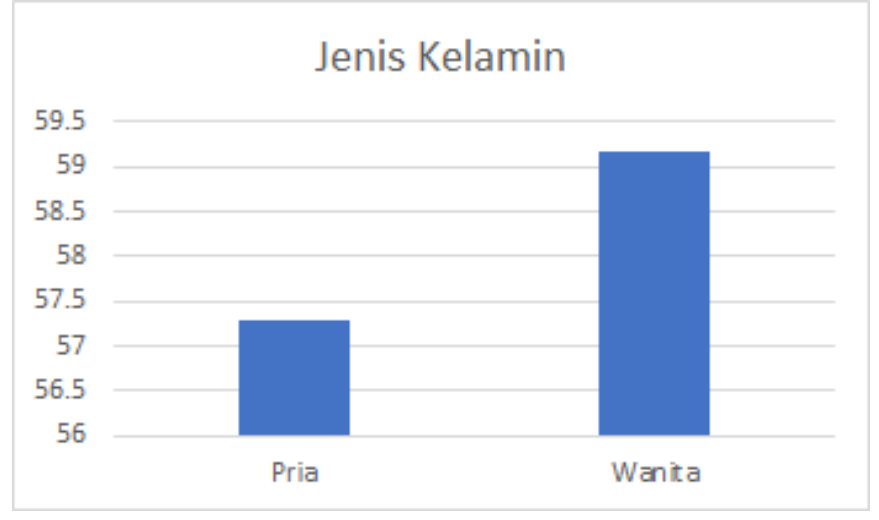

Gambar 6. Grafik Analisa Usability Berdasarkan Jenis Kelamin

Selanjutnya pada range SUS berdasarkan kategori usia, pada kategori usia $<18$ tahun, 41-50 tahun, serta $>50$ ketiganya memiliki range Good dengan SUS Final Score 60 pada rentang usia $<18$ tahun, 65,83 pada rentang usia 41-50 tahun, dan yang terakhir pada rentang $>50$ tahun sebesar 67,1875. Sedangkan pada rentang usia 18-30 dan 31-40 tahun keduanya memiliki range OK dengan SUS Final Score 56,07 pada rentang usia 18-30 tahun dan sebesar 58,33 pada rentang usia 41-50.

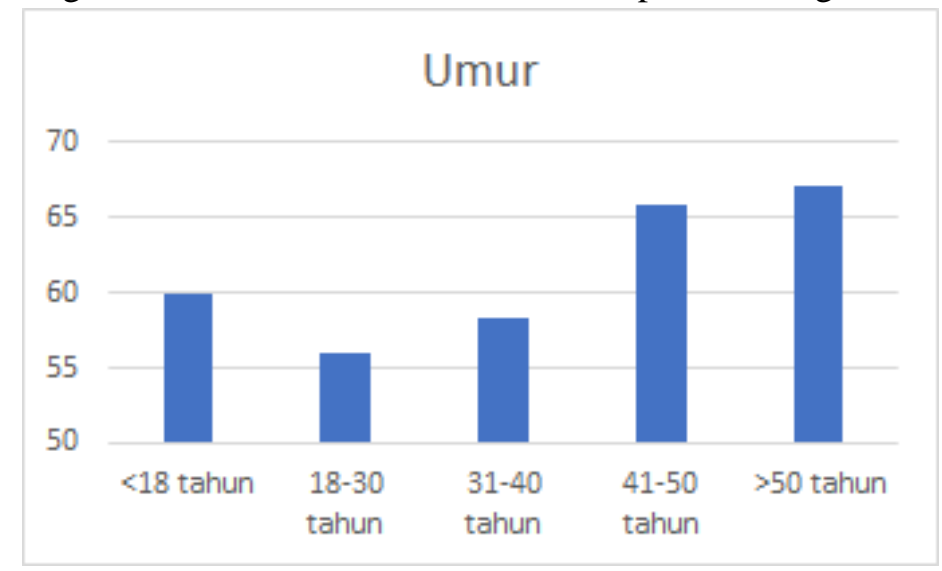

Gambar 7. Grafik Analisa Usability Berdasarkan Usia

Selain menganalisis range SUS pada satu variabel, penulis juga memperdalam analisisnya pada SUS Final Score di dua variabel. Dengan mengambil score SUS berdasarkan kategori usia dengan jenis kelamin. Hasil perhitungan SUS Final Score didapatkan angka yang sangat berbeda dengan perhitungan sebelumnya. Range Good dengan score lebih tinggi di atas 70 didapatkan pada kategori 2 variabel Pria berusia dengan rentang 40-50 tahun dan >50 tahun dengan score SUS 75. Sedangkan score SUS 70 didapatkan dari kategori wanita dengan rentang usia $<18$ tahun. Score SUS antara 60-70 didapatkan dari kategori wanita dengan rentang usia 31-40 tahun dengan score 62,5, 40-50 tahun dengan score 61,25, dan $>50$ tahun dengan score 62,5. Selebihnya diperoleh score SUS dengan range OK (range 15-59) pada kategori pria dengan rentang usia $<18$ tahun dengan score 56,67, pria berusia 18-30 tahun dengan score 52,83, pria berusia 31-40 tahun dengan score SUS 56,25, serta kategori wanita dengan rentang usia 18-30 tahun dengan score 57,87. 


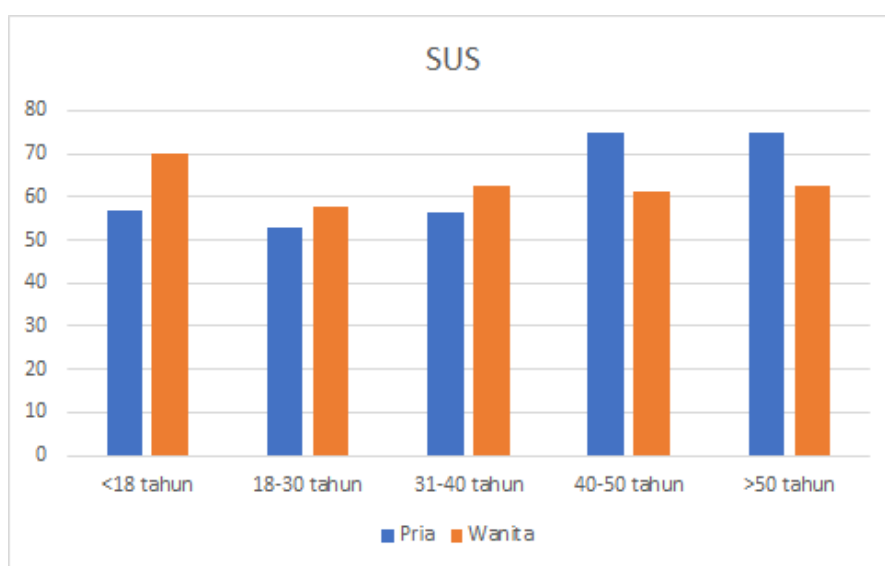

Gambar 8. Grafik Analisa Usability Berdasarkan 2 Variabel

Berdasarkan hasil survei pada 87 orang responden terdapat 48 orang yang memberikan saran untuk pengembangan aplikasi Frostid kedepannya. Di antara saran tersebut sebanyak 13 responden memberikan saran agar aplikasi dapat mengembangkan tampilan dan fitur-fitur yang disediakan, banyak diantara mengatakan bahwa tampilan aplikasi kurang menarik dan terlalu polos, selain itu fitur-fitur seperti map dan menu lainnya perlu untuk ditambahkan variasi lain agar memudahkan pengguna, terutama tutorial mengenai penggunaan aplikasi bagi pengguna baru. Sebanyak 5 responden mengeluhkan saat proses verifikasi email karena dianggap kurang efisien. Sebanyak 5 responden membutuhkan penjelasan mengenai alur aplikasi. Sebanyak 6 responden mengatakan bahwa pengembangan aplikasi diperlukan untuk kedepannya untuk memaksimalkan pengalaman pengguna. Sebanyak 9 responden mengatakan aplikasi sudah baik dan mendoakan kesuksesan aplikasi kedepannya. Berdasarkan data saran responden di atas hal utama yang harus ditingkatkan untuk pengembangan aplikasi Frostid adalah tampilan user interface dan fitur-fitur yang disediakan agar pengguna dapat lebih tertarik dan nyaman dalam menggunakan aplikasi ini. Hasil evaluasi Analisa permasalahan pengguna ditunjukkan pada Tabel 2.

Tabel 2. Hasil Evaluasi Analisa Permasalahan Pengguna

\begin{tabular}{lc}
\hline \multicolumn{1}{c}{ Saran } & Jumlah Responden \\
\hline $\begin{array}{l}\text { Memperbaiki tampilan UI dan fitur-fitur aplikasi untuk } \\
\text { memudahkan pengguna }\end{array}$ & 13 \\
\hline Verifikasi email dinilai tidak efisien & 5 \\
\hline $\begin{array}{l}\text { Memberikan keterangan / penjelasan mengenai proses } \\
\text { berjalannya aplikasi }\end{array}$ & 5 \\
\hline Meningkatkan pengembangan aplikasi untuk kedepannya & 6 \\
\hline Aplikasi dinilai sudah baik & 5 \\
\hline Aplikasi sukses kedepannya & 4 \\
\hline Lain-lain & 10 \\
\hline
\end{tabular}

\section{KESIMPULAN}

Hasil analisa usability dapat ditarik kesimpulan bahwa pengalaman pengguna terhadap usability dari aplikasi Frostid menggunakan SUS yang diterjemahkan menggunakan Adjective Scale secara keseluruhan mendapatkan hasil perhitungan yang berada pada range OK dengan SUS score antara 1559 dengan score 59,71. Sedangkan hasil analisa SUS berdasarkan 2 kategori (jenis kelamin dan usia) berada pada range GOOD. Kategori range tersebut menyatakan bahwa aplikasi Frostid berjalan baik dengan memaksimalkan pengalaman pengguna dalam menggunakan aplikasi. Dengan analisa hasil perhitungan score SUS Final Score yang didapat berdasarkan satu variabel dan 2 variabel, keduanya menunjukkan hasil yang signifikan dengan score yang didapat berada pada kategori $O K$ dan GOOD. 
Selain hasil analisis tersebut, menurut responden terpilih dari kuesioner yang telah disebarkan terdapat kekurangan pada aplikasi Frostid yaitu pada bagian tampilan user interface dan fitur-fitur di dalamnya yang memerlukan perbaikan dan pengembangan kedepannya.

\section{DAFTAR PUSTAKA}

Bangor, A., Kortum, P., \& Miller, J. (2009). Determining What Individual SUS Scores Mean: Adding an Adjective Rating Scale. Journal of Usability Studies, 4(3), 114-123.

Battleson, Brenda., Booth, Austin., Weintrop, Jane. (2001). Usability testing of an Academic Library Web site: A case Study. The Journal of Academic Librarianship vol. 27, pp 188-198.

Cahoy, Ellysa. (2021). Empirical Research in the Social Sciences and Education. PennState University Libraries: https://guides.libraries.psu.edu/emp.

Fernandez, Adrian., Insfran, Emilio., Abrahao, Silvia. (2011). Usability Evaluation Methods for the Web: A Systematic Mapping Study. Information \& Software Technology, vol. 53, pp 789-817.

Findayani, Aprilia. (2015). Kesiap Siagaan Masyarakat dalam Penanggulangan Banjir di Kota Semarang. Jurnal Geografi Media Informasi Pengembangan Ilmu dan Profesi Kegeografian, Universitas Negeri Semarang.

Galitz, W.O. (2007). The Essential Guide to User Interface Design. Third Edition. Indianapolis. Indiana: Wiley Publishing, Inc.

Kodoatie \& Sugiyanto. (2002). Banjir Beberapa Penyebab dan Metode Pengendaliannya dalam Perspektif Lingkungan. Yogyakarta: Pustaka Belajar.

Li, Yan., Li, Manchun. (2011). Application and Research on Flood Risk Assessment Decision Support System in the Lower Yellow River. IEEE.

Muqoddas, Ali., Yogananti, Auria F., dan Bastian, Henry. (2020). Usability User Interface Desain pada Aplikasi Ecommerce: Studi Komparasi terhadap Pengalaman Pengguna Shopee, Lazada, dan Tokopedia. Jurnal Desain Komunikasi Visual \& Multimedia, vol. 06, no. 01. Pp 73-82.

Nielsen, J. (2012). Usability 101: Introduction to Usability.

Sholihah, Q., Kuncoro, W., Wahyuni, S., Suwandi, S. P., \& Feditasari, E. D. (2020). The Analysis of the Causes of Flood Disasters and Their Impacts in the Perpective of Environmental Law. IOP Conference Series: Earth and Environmental Science 437(1), 012056. 